\title{
Las formas breves de Denevi, Blaisten y Amable en clave de fragmentación y discontinuidad.
}

\section{The brief forms of Denevi, Blaisten and Amable in the key of fragmentation and discontinuity.}

\author{
Gabriela Isabel Román \\ Universidad Nacional de Misiones / Consejo Nacional de Investigaciones Científicas y Técnicas \\ (CONICET) (ARGENTINA) \\ CE: gabyrom84@hotmail.com ID ORCID: 0000-0002-2273-5011
}

DOI: $10.32870 /$ sincronia.axxiii.n76.31b19

(CC) $\mathrm{BY} \cdot \mathrm{NC}$

Esta obra está bajo una Licencia Creative Commons Atribución-NoComercial 4.0 Internacional

Recibido: 31/03/2019

Revisado: $11 / 04 / 2019$

Aprobado: $11 / 06 / 2019$

\section{RESUMEN}

Este artículo presenta una problematización ante la noción de fragmento/fragmentación en la literatura. Arribamos a dos posibles entradas a este tema: el fragmento como género o "absoluto literario" y como "acontecimiento" o "fractal". Para ello abordamos las lecturas teóricas de Barthes, Blanchot, Lacoue-Labarthe y Nancy a la luz de las producciones breves de los escritores argentinos Marco Denevi, Isidoro Blaisten y Hugo Wenceslao Amable. Este trabajo forma parte de los avances en la investigación sobre las formas breves en los últimos autores mencionados, en el marco de la tesis doctoral que transitamos.

Palabras clave: Fragmento. Género. Fractal. Marco Denevi. Isidoro Blaisten. Hugo Wenceslao Amable. 


\begin{abstract}
:
This article presents a problematization before the notion of fragment / fragmentation in the literature. We arrived at two possible entries to this topic: the fragment as a genre or "literary absolute" and as "event" or "fractal". For this we approach the theoretical readings of Barthes, Blanchot, Lacoue-Labarthe and Nancy in light of the short productions of the Argentine writers Marco Denevi, Isidoro Blaisten and Hugo WenceslaoAmable. This work is part of the advances in research on the short forms in the last mentioned authors, within the framework of the doctoral thesis that we are going through.
\end{abstract}

Keywords: Fragment. Genre. Fractal. Marco Denevi. Isidoro Blaisten. Hugo Wenceslao Amable.

¿Por qué las historias eran tan pequeñas, tan minuciosamente íntimas, mezquinas y previsibles? Tan desesperadamente humanas. Ni siquiera el boicot del día de Muertos resultaría. Ni Sven cambiaría por ella sus monocopias. Ni ella cambiaría por nadie sus estados de fragmentación existencial. Todo se diluía. (Schweblin, 2018, p. 163)

Si bien la narrativa de Schewblin no forma parte del corpus de trabajo ${ }^{1}$ que transitamos, una captura del relato citado nos detiene en una reflexión acerca de la fragmentación en la literatura, en la selección de trozos (de la memoria, del contexto, de posibles agenciamientos infinitos) que un sujeto toma y ensambla con otros para formar un texto abierto, móvil, múltiple. El individuo es un fragmento íntegro, autónomo que necesita de "otros" (como él) para configurar su universo, su entorno y su ser. El arte y la filosofía se sirven de ello, lo exponen, lo re-presentan de una manera también fragmentada (Nancy, 2003).

\footnotetext{
${ }^{1}$ Cabe mencionar que este trabajo se inscribe en las lecturas y análisis de la tesis doctoral (que se encuentra en proceso de elaboración) "El microrrelato en tres escritores argentino: Marco Denevi, Isidoro Blaisten y Hugo W. Amable", dirigido por la Dra. Mercedes García Saraví.
} 
Los fragmentos se eligen de la arbitrariedad de la experiencia. Selección y combinación. En este punto surge una inquietud: ¿sobre la base de (toda) la literatura está la fragmentación? Sobre la base del arte, de la estética está la fragmentación para Blanchot (1973, 2008), para Nancy (2003). Siempre hay un poeta, narrador, dramaturgo que recorta, decide qué escribir, desde qué lugar. Sin caer en un análisis disfrazado de estructuralismo, el letargo teórico y la lectura de narrativa nos paralizan en la idea de que existe un mecanismo de escritura fragmentaria que cobra énfasis en ciertas producciones actuales ${ }^{2}$ pero que tiene una larga historia: desde la mitología grecolatina, los diálogos socráticos, El Quijote de la Mancha, hasta el Romanticismo y la inauguración del género (punto nodal de la discusión). La brevedad que incorporan los románticos luego se ve en los simbolistas, los modernistas y las vanguardias, en la teoría y en la crítica literaria.

Los románticos alemanes abren el camino hacia, por un lado, una perspectiva que nos permite conversar y analizar las implicancias y recursividades de la literatura, la teoría y la crítica bajo lo que denominan "absoluto literario" ${ }^{3}$, literatura que es teoría, teoría que es literatura mediante la escritura fragmentaria. El "absoluto literario" da lugar a la configuración del fragmento como género, que se caracteriza por su autonomía, anonimato, y su efecto erizo (Lacoue-Labarthe \& Nancy, 2012). Nancy, en El sentido del Mundo (2003), suma otra variante de fragmento vista como fractal, como acontecimiento que irrumpe en el arte como quiebre, ruptura que dispone su

\footnotetext{
${ }^{2}$ Esta novela de Schewblin encadena historias de un grupo de personajes bajo una técnica de relato intercalado. Pero además nos trae a la memoria, la trilogía de Pablo Ramos con el personaje Gabriel en la que los fragmentos irrumpen el periodo vital que el narrador-personaje cuenta, lo mismo sucede con algunos relatos de Fabian Casas, por citar su novela Ocio y su libro de cuentos Los leminngs y otros. Esto en cuanto al género novela. También tenemos que mencionar la explosión de las formas breves manifiestas a través de la minificción, el teatro y la poesía breve.

${ }^{3}$ Lacoue-Labarthe y Nancy comentan que esta noción de "absoluto literario" surge del "primer romanticismo", el de Jena, que inaugura el primer proyecto teórico en la literatura. Encarna el surgimiento de una crisis del romanticismo novelesco y corresponde a la crisis económica, social, política y moral de los últimos años del siglo XVIII que son descriptos en los fragmentos que componen la revista Athenaeum, creada y constituida por los hermanos Schlegel, August Wilhelm y Friedrich pero heredada de Chamfort, Pascal y Montaigne.

La matriz de esta revista es la escritura colectiva a la que se le suman los rasgos: utilización de todos los géneros (la noción de género cobra relevancia); fragmento; cuestionamiento a la propiedad literaria; y prueba de anonimato. El romanticismo es la inauguración del absoluto literario; el romanticismo no es ni "literatura" "teoría" de la literatura sino la teoría misma como literatura o la literatura produciéndose y produciendo su propia teoría: "la literatura como autocrítica y la crítica como literatura" (cf. Pág. 42). El hecho de que la literatura vea que desde Platón y Aristóteles se propone la unión de la poesía y la filosofía.
} 
acceso abierto, simbólico. Claramente podemos decir que reconocemos dos entradas, dos clave para problematizar la noción de fragmento: 1. Como absoluto literario, como género; 2, como fractal, acontecimiento.

\section{El absoluto literario}

Barthes crea una estética fragmentaria que atraviesa sus producciones desde Mitologías (1957) hasta su libro póstumo Incidentes (1987) en el que los límites entre el discurso literario y el teórico son ínfimos; lo mismo sucede en El Imperio de los signos (1970) y Roland Barthes por Roland Barthes (1978) donde lo autobiográfico se confunde y se cuela en notas de apariencia teóricocrítica. Esta manera de escribir pone en tensión la mirada literaria y teórica que hacen sus lectores, por lo que habilita ingresar a sus textos por lugares distintos de acuerdo a la circunstancia de lectura y el ejercicio de escritura/reescritura.

"Leer es siempre reescribir" comenta Eagleton (1998, p.24) cuando dice que encontramos un Homero y un Shakespeare diferentes en cada contexto y época ya que los textos cobran valores y se someten a evaluaciones distintas según el lector. Sin hacer en un recorte extremo de la propuesta de Eagleton, nos interesa reconocer la posición que cobra el público cuando decide leer como "literario" un texto que no fue concebido como tal, aquello que la gente hace con un texto y con lo que el escrito hace con la gente, independientemente de lo pragmático que le resulte al lector el ejercicio. "Algunos textos nacen literarios; a otros se les impone el carácter literario" (Eagleton. 1998, p. 20).

Desde el lado de la escritura filosófica en particular y de las distintas formas de expresión del pensamiento en general, Blanchot en "El pensamiento y la exigencia de discontinuidad" reconoce en los aportes de Pascal y en su discurso (desunido, interrumpido) filosófico la concepción de fragmento como coherencia, pensamiento viajero compuesto por afirmaciones que exigen la separación, la irrupción, la discontinuidad. De esta manera lee a Nietzsche y su escritura fragmentaria (1973). 
Literatura, filosofía, teoría y crítica se mueven en un vaivén infinito, pujante, indefinido donde la fragmentación es una clave que acredita al movimiento perpetuo.

En un recorrido por blogs ${ }^{4}$ descubrimos la recurrencia del texto "Un millón de sandías" de Isidoro Blaisten, leído como microrrelato aunque éste no forma parte de lo que el autor organiza como su narrativa, al contrario lo podemos ver en Anticonferencia (1983/2017) que se etiqueta como obra ensayística. Al interior del libro lo encontramos junto a otros doce micro-ensayos que conforman la sección "Para qué sirve un poema" por lo que adquiere un sentido determinado cuando es leído en la integridad de la que forma parte. Blaisten recurre a la típica polifonía del ensayo para construir una concepción teórico-crítica acerca de la poesía, del "ser" poeta y del tiempo de/en ambos. Pero "Un millón de sandías" (relato que alude a los sueños que construye el poeta) o "Sexo y sufrimiento" (historia de una pareja que va al cine) resultan perfectas narraciones que extraídas adquieren autonomía y completud capaz de provocar lecturas disímiles, arbitrarias al contexto de producción y circulación en el que se insertan.

La fragmentación, el desgarro de la integridad de la obra, posibilita la utilización escritural discontinua, disidente, accidentada, independiente. El uso y el valor pragmático del texto, su carácter literario o de reflexión crítica se ponen en juego en la particularidad de cada sujeto que visita el libro o recorre las vidrieras digitales.

Las figuras del habla misionera (1980) de Hugo Wenceslao Amable es un libro caratulado como ensayo lingüístico en el que el autor indaga los distintos giros dialectales [recordemos que además de narrador, Amable ejercía la función de lingüista en el campo misionero] y los modos en que la frontera transforma la lengua en construcciones sintácticas desterritorializadas, nutrida del habla que va y viene de un lado al otro del río, llevando y trayendo partículas gramaticales que dislocan la semántica para conseguir sentidos específicos en cada época y espacio del territorio en

\footnotetext{
"Esta indagación formó parte de la ponencia "Isidoro Blaisten en el blog: una forma de volver a leer sus microrrelatos" escrita para el Congreso Internacional Orbis Tertius, 2015.
} 
la que se emplean ${ }^{5}$. Recuperar el habla es un acto que pone en tensión la teorización lingüística y gramatical contaminada de narración. Las novelas, cuentos y microrrelatos donde prima lo literario también incluyen fragmentos de reflexión sobre la lengua mediante la ruptura de la historia y la inserción de un término, su concepto, uso e historia. Es inevitable percibir el eco que nos deja la lectura de Eagleton: lo literario, sus usos por parte del lector, su sentido pragmático, aquello que no fue creado como literario; y de los románticos: lo literario devenido teórico, lo teórico como literario, el fragmento.

La escritura es un círculo. Lo mismo sucede con Barthes: "Un joven limpiabotas un poco loco, desarticulado, siempre se precipita sobre mí proponiéndome bajo la nariz con insistencia: yo, lustrar, chino (adjetivo de perfección)" (2016, p. 40). Este fragmento y los otros que componen Incidentes pueden ser leídos como fracciones teóricas sobre el amor y lo sensible que el autor dilata a lo largo de varias producciones, pero la irrupción fragmentaria conlleva a leerlo como narración, como notas ficcionales que guardan (o no) relación con las demás al interior del texto. El discurso fragmentario evidencia un ejercicio escritural, el devenir de un estilo interrumpido, discontinuo, recortado como "un incidente", un accidente.

En este sentido, Ette en su artículo “Perspectiva de la nanofilología” (2010) reconoce una manera más para denominar estas formas fraccionadas de hacer teoría a través "microtextos". La noción de "escritura corta" que aparece en Roland Barthes por Roland Barthes es otro modo de microtexto que, según Ette, incluye distintas maneras de hacer micro-teoría en la que la música, la pintura, la literatura provocan un texto que necesita comenzar y recomenzar cada vez, un instante de goce y placer que es interrumpido y discontinuo, como una puesta en escena esquizofrénica.

[Inevitablemente el fractal se cuela en la escritura pseudo-teórica barthesiana que promueve líneas discursivas que salen del texto y retornan constantemente, lo que vuelve difícil hablar de fragmento como género sin reconocer esta capacidad plural que cada micro-universo contiene dada la condensación discursiva. De la misma manera ocurre con las notas y

\footnotetext{
${ }^{5}$ La provincia de Misiones, donde ubicamos la obra de Hugo Wenceslao Amable, se encuentra en el noroeste de la República Argentina, en una zona de frontera con Paraguay y Brasil, lo que hace a un territorio plurilingüe e híbrido, aspecto que invade la literatura y las reflexiones sobre la lengua de sus escritores.
} 
anticonferencias de Blaisten, en "Para qué sirve un poeta" alude a las lecturas de escritores como Pessoa, García Lorca, Borges, Pavese, Ceselli, Maiacovski, entre otros pero también al cine con "La princesa que quería vivir" (William Wyber), al tango, a la filosofía y a la Biblia]. Paradoja de la fragmentación. Cada micro universo textual es autónomo, podemos sacarlo de su conjunto y tomarlo desde la individualidad, pero a la vez responde a la totalidad del apartado, del libro, de la literatura y la cultura.

El fragmento, para los teóricos románticos, es proyecto, proyección inmediata cuyos bordes responden a una deformidad desgarrada que le permiten conectarse con otros y formar así un sistema.

Es inacabado pero autónomo, coagula en sí mismo, repliega sus límites frágiles en su propia conciencia, interviene la dispersión de la que forma parte como destello íntegro, absolutiza su contingencia nómada, la disrupción transforma su in-finitud en retoque final (Nancy, 2003). "Totalidad fragmentaria": los micro-ensayos/relatos de Barthes, de Blaisten, de Amable secuestrados de su obra y leídos en la arbitrariedad cronotópica. El fragmento no se sitúa en ninguna parte sino que está simultáneamente en el todo y en la parte, la totalidad es el fragmento en sí mismo (una miniatura, un microcosmos de la obra) y la totalidad se origina por la co-presencia con las partes.

Los románticos aluden, además, a otro género: la idea. La continuidad en la discontinuidad que se realiza en una obra en la que integra o irrumpe el fragmento se debe a un aspecto histórico que reconoce la anulación del problema formal, "el fragmento es esa forma sin forma" (LacoueLabarthe \& Nancy. 2012, p. 231), la profundización de la forma es una utopía, es una cuestión filosófica que conlleva a la obstinación subjetiva, a la autoproducción. La problemática del género está puesta en estas bases, los límites son ineludiblemente difusos, establecer una estructura única es equívoca, cada genio individual crea una obra/un género individual que puede seguir una nomenclatura histórica pero con una sustancia propia (Williams, 2009).

La obstinación da paso a una interminable o imposible autoconcepción del sujeto que puede manifestarse en ideas; podemos pasar del fragmento a las ideas, es decir, a pensamientos infinitos, 
autónomos, móviles. La idea es una representación que existe para sí, que está formada en sus propios límites lo que no le permite constituir una totalidad sistemática, pero en su independencia la connotación filosófica que contiene puede ser inagotable. Es el género moral del fragmento, su aspecto es próximo a la máxima o la sentencia y como éstas contiene un discurso imperativo y dialógico en el que, entre el enunciador y el receptor se establece una relación de imitación.

El discurso sentencioso conlleva como función la ejemplaridad, el modelo moral: "En su versión moderna, en suma, el género moral del fragmento supone la entrada de lo paradigmático y de lo ejemplar en la esfera de la Subjetividad. Es modelo, y modelo absoluto, quien se arroga el derecho de decir "Yo (la verdad), hablo...". (Lacoue-Labarthe \& Nancy, 2012, p. 238)

La esencia del artista es la autoproducción que de acuerdo con la época cumple el rol de educador, iniciador, modelo, formador, revelador de la verdad. La forma fragmentaria de las ideas en las escrituras de Blaisten y Amable integran textos un poco más extensos en la parataxis general y así admiten lecturas disímiles de los microrrelatos o suscitan lecturas paralelas de ideas independientes de los textos como es el caso puntual de la sección "El revés de los refranes" de Isidoro Blaisten, en la que cada relato parte de un título compuesto por un refrán.

Denevi consigue componer un conjunto de ideas/frases que se agrupan bajo el título "Pensamientos/ingeniosidades del señor Perogrullo" ${ }^{6}$.

La paradoja en la concepción teórica que establece el Romanticismo es la de entender a la Idea como una forma genérica que recae sobre lo moral, sobre la profundización del sujeto ante

\footnotetext{
${ }^{6}$ Algunas de las reflexiones sobre este corpus forman parte de la ponencia "Pensamientos del señor Perogrullo" de Marco Denevi y la serialización metadiscursiva, presentada en el IX Congreso Internacional de Minificción, realizado en el 2016 en la Universidad Nacional del Comahue. La RAE designa a la palabra Perogrullo como personaje ficticio a quien se atribuye presentar obviedades de manera sentenciosas, y al término Perogrullada como coloquialismo que determina verdad o certeza que, por notoriamente sabida, es necedad o simpleza el decirla. De acuerdo con el texto Profecías, de un escritor del siglo XV español que se hacía llamar Evangelista, podemos deducir que Perogrullo es un personaje literario que emitía vaticinios y cuyo nombre es una combinación de Pero Grillo (en Cantabria denominaban Pedro o príncipes a los grillos). Su verdadera procedencia se desconoce, pero en España circulan algunos relatos tradicionales donde aparece un sujeto que emite predicciones cargadas de verdaderas necedades, un individuo que forma parte del imaginario popular. Este personaje es retomado por Francisco de Quevedo en su poema "El sueño de la muerte", en el que se emite profecías a las que el poeta llama "perogrulladas". Posteriormente, Cervantes pone en la voz de Sancho una referencia al acto de decir perogrulladas.
} 
una perspectiva filosófica determinada, cuando Jolles $(1972)^{7}$ reconoce que la ciencia literaria que inaugura este movimiento deja de lado una serie de géneros -entre los que aparece la sentencia/proverbio- en los que prima la lengua de la comunidad hecha forma para dar lugar a ciertas expresiones de culto.

Mediante la parodia genérica de las ideas/fragmentos, los Pensamientos de Perogrullo se presentan como una construcción dialógica que antes de moralizar al espectador lo hace cómplice de un juego burlesco expuesto en sentencias inconexas, heterogéneas, o frases inventadas o citadas: "Aquello de "dime con quién andas y te diré quién eres" vale también para los que andan solos" (Denevi, 1984, p. 21); "Pobre pero honrado ¿No deberían decir los ricos? Rico pero honrado" (p. 135); "Como toda revolución cree ser la única, toda revolución quiere ser la última y apenas triunfa se vuelve reaccionaria" (p. 199).

La sentencia encuentra en el proverbio su actualización, una forma que atraviesa todas las capas sociales y toma rasgos particulares en cada una de ellas, así Jolles (1972) habla de una capa inferior, una alta (en estos niveles se mueven los proverbios) y una superior (a la que le corresponde el pensamiento -punto de encuentro con los románticos alemanes). En las obras de Denevi, Blaisten y Amable podemos encontrar fragmentos que aluden paródicamente a cada estrato; en algunos casos es puesta como una frase célebre tomada de un personaje que el lector puede reconocer y reutilizada de acuerdo con la experiencia vivida en una comunidad, en una época, en un círculo social determinado.

Como decíamos ut supra, en la versión de 1991 de El mago, Blaisten incorpora un conjunto de relatos que parten de un refrán que luego es trastocado en la narración; de la misma manera aparecen las "Historietas literarias" de Amable pero con una expresión de uso

\footnotetext{
${ }^{7}$ Jolles se ocupa de revisar la obra en sus comienzos, en cómo la lengua conduce el texto a la literatura, cómo, dónde y cuándo la lengua llega a ser forma, crea, transforma universos, se poetiza, cuando un fenómeno que se repite conquista el sistema de la cultura, aunque no pertenezca al mundo de la estilística, ni de la retórica ni de la poética, aunque no sean parte de la escritura. Composiciones que se asocian a la oralidad, a la vida y al quehacer/trabajo del campesino/productor (familia), el artesano/creador (el gremio) y el sacerdote/intérprete (la congregación). En este campo, el autor ubica a la hagiografía, la leyenda, el mito, el enigma, la sentencia, el casus, la memorabile, el märchen (o los cuentos de hadas) y el chiste.
} 
popular/local/misionero como título. En ambos corpus el fragmento entra en un vaivén yuxtapuesto que pone en conflicto la noción romántica de "idea" (en el título), portadora de una historia colectiva, de un sentido acabado, independiente, moralizante, $y$, la perspectiva de fragmento/fractal como acontecimiento discontinuo que aporta la narración dislocada que corresponde a la sentencia, o a la frase del pueblo con la que inician los relatos. Solo a modo de ejemplos:

\section{Más vale pájaro en mano que cien volando}

Eso le enseñaron. Lo mamó desde la cuna. Lo oyó desde sus primeros pininos. Se hizo carne en él. Entonces dejó volar los noventa y nueve pájaros y apretó fuerte, bien fuerte, el que tenía en la mano. El pájaro murió asfixiado. (Blaisten, 1991, p.182)

\section{Dormir a pierna suelta}

Estaba sumamente cansado. Se echó a dormir un rato. Como la oscuridad durmió a pierna suelta. Cuando se despertó, no encontraba su pierna: había caído al costado de la cama. (Amable, 2018, p. 116)

\section{Fragmento como fractal}

Con estos ejemplos accedemos a la segunda perspectiva acerca de esta noción. La lectura rápida de estos relatos producto de la brevedad da cuenta de una representación venida en presencia, en acontecimiento de aparente sentido efímero que guarda en su interior un cúmulo de posibles significados gracias al fractal del título en relación con la narración, de la irrupción de referencias que descubren el palimpsesto ante un lector atento, y ante los modos y usos que éste realiza.

Cada detalle es enlazado ingenuamente, inesperadamente, lo que torna a la escritura en un juego de comienzos y re-comienzos, una multiplicidad de placeres. Por ello, el fragmento es un goce inmediato, un suspiro, una aparición discursiva de deseo. Cada idea, cada germen surge en cualquier parte y en cualquier momento. Se trata de la emergencia de la escritura y por lo tanto de la lectura. El re-comienzo barthesiano, la recursividad, lo inacabado y autónomo en un sistema total es el efecto de un devenir paradójico, de un "eterno retorno" que se instala mediante la grieta, la 
irrupción de cosas, sujetos, proposiciones, palabras que crean agenciamientos (Deleuze, 2010), nuevas relaciones que subvierten el cierre y la totalidad, dejan abierta la puerta para la creación de algo nuevo, repetido pero singular. El detalle, los recortes como técnicas de infracción voluntaria (Barthes, 2003) provocan discontinuidad, un pensamiento en migajas que pone en movimiento sentidos fracturados.

Leer es reescribir, escribir es reescribir, es comenzar una y otra vez. Las formas breves ponen al desnudo este procedimiento barthesiano (si podemos llamarlo así) ya que el escritor de minificción condensa pero no agota los sentidos en el texto, se queda con el deseo de seguir el garabateo que lo lleve a leer, a escribir, a reescribir incansablemente.

Las frases hechas, los refranes, las perogrulladas son portadores de mundos de ficción, a los que cada autor le suma otros, y el lector reconstruye los suyos. Estas textualidades dan cuenta del fragmento como acontecimiento en el que prima lo inconmensurable del espacio (pero también del tiempo) de la apertura (Nancy, 2003) que provoca la presencia enunciativa como disparadora de nuevas ficciones.

Las obras están hechas de piezas/fragmentos que se organizan de modo cíclico como una escritura en redondo que nunca cierra porque es incompleta, inacabada. Cada pieza tiene la particularidad de bastarse a sí misma dado que al interior de cada tejido se manifiesta la "parataxis", y a la vez el fragmento es un intersticio con aquellos que conforman el texto total, con sus "vecinos" (Barthes, 1978). Intermezzo, intercalado.

Esto último nos lleva a entender que cada minificción -como texto total- puede ser desmembrado de un tejido mayor y a la vez su entramado ficcional enlaza puntadas como líneas fractales ${ }^{8}$ con aquellas textualidades que lo acompañan en el libro.

\footnotetext{
${ }^{8}$ Desde las teorías de la minificción y la nanofilología queremos mencionar el aporte de dos autores a este concepto, el primero Ottmar Ette, con un artículo ya citado en este trabajo, quien piensa el fractal desde los estudios del matemático Benoit Mandelbrot como una geometría de la literatura, una morfología de lo amorfo: "los patrones fractales acumulan y contienen la totalidad de una estructura, para la que funcionan a la vez como llave semántica y estructural. La estructuración fractal de los microrrelatos (logrados) no solamente trasciende las continuidades de una geometría en cierto sentido euclidiano-literario tanto en el nivel de la producción como de la recepción; además sistemas de
} 
Este es el caso más reiterado en la que el lector de formas breves se encuentra: por lo general y ante la brevedad, los textos se aglomeran bajo títulos abarcadores como "Para qué sirve un poeta", o "El revés de los refranes", estructuras sintácticas que aportan a una semántica común, unificadora, pero a la vez, cada texto, desde su completud y autonomía con el dossier o el apartado genera nuevas conexiones con otros textos del mismo autor, o con textos y autores diversos de la literatura universal y la cultura en general mediante "detalles", partículas al interior del tejido narrativo.

Estos elementos producen una discontinuidad y una recursividad en la lectura y en la escritura mediante personajes, palabras, acontecimientos. En Denevi podemos encontrar una serialización (Deleuze, 2010) infinita según las relaciones/agenciamiento en el comienzo y recomienzo de un acontecimiento, por ejemplo cuando alude a "Judas" en los microrrelatos "El maestro traicionado", "La enunciación del traidor", "Otra versión", "Sobre Judas Iscariote", "Proposiciones sobre el amor divino", "Segundo intermedio: los amigos de los hombres célebres", "Ningún amor satisface al resentido", "Fin de toda discusión teológica respecto de Judas", "Prestigioso Judas", "Impaciencia del corazón", entre otros títulos.

El fragmento es "arte del estribillo", despojado de los deslices de la historia aunque encadenado a ella (Nancy, 2003). Denevi nos brinda muchos ejemplos próximos al expuesto, la historia, la religión, la literatura universal son su ventana por la que ingresa sin pedir permiso para reescribir recursivamente sus pasiones, para petrificar una imagen que luego fractura sin cesar.

referencias gracias a su altísima densificación, en los que sus flashbacks y flashforwards remiten no solo a un conjunto (por ejemplo serial) de microrrelatos cotextuales, esto es, distribuidos en un mismo libro." (Cf. P. 120)

En segundo lugar, Yvette Sánchez en su artículo "Nanofilología. Miniaturización fractal", lo define como "...un sistema complejo que se multiplica hacia el infinito a partir de sí mismo, objeto semi-geométrico (de geometría irregular) cuya estructura básica se repite en diferentes escalas según un proceso recursivo que se produce en una escala infinita y que hallamos a menudo en la naturaleza: en los copos de nieve, las líneas costeras, la circulación de la sangre, los bronquios, el cerebro. Se trata de una especie de universo virtual por definición infinito. Cada zoom sobre una parte de la imagen revela nuevos detalles, nuevas formas, nuevos mundos. Los fractales describen la geometría de la naturaleza cuyas formas complejas, irregulares y veleidosas escapan a la geometría clásica. Repetición de formas similares a distintas escalas, splitting, una bifurcación respectivamente en ramificación, iteración e intercalación." (Cf. p. 144) Este punto de vista que coincidimos cuando abordamos la minificción de Denevi, Blaisten y Amable en relación con los teóricos que proponemos en este artículo. Coincidimos con este punto de vista cuando abordamos la noción de fractal desde la perspectiva de Nancy. 
Cuando Blanchot (1973) se inmiscuye en la escritura de Nietzsche alude a un habla fragmentada que ignora la contradicción cuando es contradicción: dos textos pueden oponerse pero en realidad se ubican uno al lado del otro, uno sin relación con el otro, pero relacionado, escrituras con un espacio en blanco (o agregaríamos para los casos de Denevi, Blaisten, Amable, espacios escritos: narraciones, ficciones, ensayos sin aparente relación semántica) que no separan ni juntan sino que llevan, en la diferencia, en sus límites el sentido, deslizándose fuera de sí pero reconduciéndose a sí. Esto provoca un pensamiento aleatorio, plural, discontinuo. El habla del fragmento es el habla del intermedio. Blanchot $(1973,2008)$ no utiliza el término fractal pero este movimiento de desplazamiento espacial y retorno a sí que otorga a la escritura nietzscheniana responde a parámetros fractales.

Esta concepción es relacionada por el autor con el concepto nietzscheniano del "eterno retorno", una perpetua repetición del ser en devenir, de frases hechas, de proverbios, de refranes, de historias sobre un mismo personaje contadas con focalizaciones diferentes una y otra vez. El eterno retorno de lo mismo pero diferente. Diferencia y repetición, comienzo y recomienzo del arte que no discurre sino fragmenta, aquí coinciden Blanchot, Barthes y Nancy. Arte que sale y en el exterior de sí encuentra el sentido del sentido, en la diferencia, en el toque de placer.

\section{Conclusión inconclusa}

En las notas introductorias que Miguel Dalmaroni (2018) nos propone para comenzar a problematizar la noción de "discontinuidad" como "operador para leer", aparece la idea de hallar tesis, conceptos y teorías emparentadas sobre discontinuidad que nos permiten encontrar “herramientas de indagación para escribir una lectura" (Dalmaroni, 2018, S/D de página) crítica.

En el ejercicio recurrente de la tarea del investigador revisamos conceptos -como "fragmentación”, "género", "idea”, "fractal”, "discontinuidad” e "irrupción/interrupción”, "placer", "recomienzo" - que nos sirven para inmiscuirnos en la trama teórica, crítica y ficcional de Denevi, Blaisten y Amable, pero también de Barthes, escritor que nos promueve a revisión constante y 
placentera de los modos escriturales de los autores del corpus y de otros que transitan nuestro laboratorio de investigación.

La noción de fragmento/fragmentación es el punto nodal de este trabajo. Navegar en sentido discontinuo por las distintas teorías nos lleva a reconocer que podemos entender el fragmento a partir de dos variantes: 1. Como género absoluto, tipo que nos lleva a leer literatura y teoría con la misma lente; 2 . Como fractal, acontecimiento, tipo que pone en tensión el texto, su multiplicidad y representación. Ahora bien, navegar en sentido discontinuo también nos demuestra que puede existir una clasificación que tenga más de dos tipos (aún no lo descubrimos), o que los antes expuestos sean en realidad uno solo (un solo tipo, ¿el género es siempre fractal?). En este caso, concluir con datos o conceptos certeros parece un frenesí agobiante, por ello preferimos la duda, el juego, y la practicidad de un concepto móvil que oficie de "operador de lectura", de clave cada vez que ingresemos a los textos.

\section{Referencias}

Amable, H. W. (1980). Las figuras del habla misionera. Posadas: Editorial Universitaria,

Amable, H. W. (2018). Historietas literarias. En Narraciones, poemas e historietas literarias. Posadas: Editorial Universitaria,

Barthes, R. (1978). El círculo de los fragmentos, El fragmento como ilusión, Del fragmento al diario. En Roland Barthes por Roland Barthes. Barcelona: Editorial Kairos.

Barthes, R. (2003). Literatura y discontinuidad. En Ensayos críticos. Buenos Aires: Seix Barral.

Barthes, R. (2016). Incidentes. Buenos Aires: Biblioteca de los confines.

Blaisten, I. (1991). El mago. Buenos Aire: Emecé.

Blaisten, I. (2017). Anticonferencias. Buenos Aires: Tusquets,

Blanchot, M. (1973). La ausencia del libro. Nietzsche y la escritura fragmentaria. Buenos Aires: Calden.

Blanchot, M. (2008). El pensamiento y la exigencia de discontinuidad. En La conversación infinita. Madrid: Arena Libros.

Dalmaroni, M. (2018). Discontinuidad. Notas introductorias. Material para el curso de posgrado Teorías de la literatura: discontinuidad, interrupción y resto. UNNE. Resistencia. 
Deleuze, G. (2010). Lógica del sentido. Buenos Aires: Paidós.

Denevi, M. (1984). Falsificaciones. Obras completas tomo 4. Buenos Aires: Corregidor

Eagleton, T. (1998). Introducción: ¿Qué es la literatura?. En Una introducción a la teoría literaria. México: Fondo de Cultura Económica.

Jolles, A. (1972). Formas simples. Chile: Editorial Universitaria.

Ette, O. (2009). Perspectivas de la nanofilología. Revista Iberoamericana. América Latina, España, Portugal. (36), $109-125$

Nancy, J. y Lacoue-Labarthe, F. (2012). El absoluto literario. Teoría de la literatura del romanticismo alemán. Buenos Aires: Eterna Cadencia.

Nancy, J, L. (2003). El arte, fragmento. En El sentido del mundo. Buenos Aires: La Marca.

Sánchez, Y. (2009). Nanofilología. Miniaturización fractal. Revista Iberoamericana. América Latina, España, Portugal. (36). 143-152

Schweblin, S. (2018). Kentukis. Buenos Aires: Literatura Random House.

Williams, R (2009). Los géneros. En Marxismo y literatura. Buenos Aires: La cuarenta. 